\title{
Bed-integrated local exhaust ventilation system combined with local air cleaning for improved IAQ in hospital patient rooms
}

Bivolarova, Mariya Petrova; Melikov, Arsen Krikor; Mizutani, Chiyomi; Kajiwara, Kanji; Bolashikov, Zhecho Dimitrov

Published in:

Building and Environment

Link to article, DOI:

10.1016/j.buildenv.2016.02.006

Publication date:

2016

Document Version

Peer reviewed version

Link back to DTU Orbit

Citation (APA):

Bivolarova, M. P., Melikov, A. K., Mizutani, C., Kajiwara, K., \& Bolashikov, Z. D. (2016). Bed-integrated local exhaust ventilation system combined with local air cleaning for improved IAQ in hospital patient rooms. Building and Environment, 100, 10-18. https://doi.org/10.1016/j.buildenv.2016.02.006

\section{General rights}

Copyright and moral rights for the publications made accessible in the public portal are retained by the authors and/or other copyright owners and it is a condition of accessing publications that users recognise and abide by the legal requirements associated with these rights.

- Users may download and print one copy of any publication from the public portal for the purpose of private study or research.

- You may not further distribute the material or use it for any profit-making activity or commercial gain

- You may freely distribute the URL identifying the publication in the public portal 
Bed-integrated local exhaust ventilation system combined with local air cleaning for improved IAQ in hospital patient rooms

Mariya P. Bivolarova ${ }^{\mathrm{a}, *}$, Arsen K. Melikov ${ }^{\mathrm{a}}$, Chiyomi Mizutani ${ }^{\mathrm{b}}$, Kanji Kajiwara ${ }^{\mathrm{c}}$, Zhecho D. Bolashikov $^{\text {a }}$

${ }^{a}$ International Centre for Indoor Environment and Energy, Department of Civil Engineering, Technical University of Denmark, Niels Koppels Allé, building 402, DK-2800 Lyngby, Denmark ${ }^{b}$ Department of Clothing and Textiles, Otsuma University, 12 Sanban-cho 102-8357 Tokyo, Japan

${ }^{c}$ Faculty of Engineering and Design, Kyoto Institute of Technology, Matsugasaki, Sakyo-ku 606-8585 Kyoto, Japan.

*Corresponding author. Tel.: +45 452540 32, Fax: +45 45932166

E-mail addresses: mbiv@byg.dtu.dk (M.P. Bivolarova), akm@byg.dtu.dk (A. K. Melikov), mizutani@otsuma.ac.jp (C. Mizutani), kajiwara@shinshu-u.ac.jp (K. Kajiwara), zdb@byg.dtu.dk (Z. D. Bolashikov) 


\begin{abstract}
The performance of a ventilated mattress (VM) used as a bed-integrated local exhaust ventilation system combined with air cleaning fabric (acid-treated activated carbon fibre (ACF) fabric) was developed and studied. The separate and combined effect of the VM and the local air cleaning for reducing the exposure to body generated bio-effluents in a hospital room was determined. Full-scale experiments were conducted in a climate chamber furnished as a single-bed patient room. Two heated dummies were used to simulate a patient and a doctor in the room. The patient was lying on a bed equipped with the VM. The patient's body was covered with either a cotton sheet or with the ACF material used as a blanket. Ammonia gas released from the patient's groins simulated the body generated bio-effluents. At the location of the groins the surface area of the VM was perforated through which the contaminated air of the bed micro-environment was exhausted. Two modes of operation were studied: 1) the exhausted polluted air was discharged out of the room and 2) the polluted air was cleaned by the ACF material installed inside the mattress and recirculated back into the room. Both modes of operation efficiently reduced the generated bio-effluents in the room with about $70 \%$. Reduction in the exposure to body-emitted ammonia was up to $96 \%$ when the VM was operated at only $1.5 \mathrm{~L} / \mathrm{s}$ and the ACF was used as a blanket.
\end{abstract}

Keywords

Bed-integrated local exhaust ventilation; Ventilated mattress; Air cleaning textiles; Indoor air quality; Body-emitted pollutants; Exposure 


\section{Introduction}

Patient rooms in health care facilities, such as hospitals, require ventilation to provide a healthy and comfortable environment for patients' recovery and efficient performance of medical staff [1]. Indoor air quality (IAQ) is more critical in these facilities than in most other building environments, because of the hazardous microbial and chemical agents present (many of which airborne) as well as the increased susceptibility of the patients [1]. Studies have shown that hospital employees reported more indoor air problems and indoor air related symptoms, such as sick building syndrome symptoms, than staff employed in office buildings [2,3]. Thus, it is important to provide proper air conditioning of health care facilities in order to meet the needs of all occupants, i.e. patients, staff and visitors.

Most often, mechanical ventilation is used to conditioned and ventilate the various hospital units. Natural ventilation can also be applied, but there is still need to develop a detailed design and operation guide for hospital engineers and architects [4].

Efficient air distribution within a patient room will depend on many factors including: ventilation rate, choice of air distribution principle, location of the supply and exhaust air terminal devices (ATDs), heat load distribution, occupants' activities, etc. [5]. The conventional mechanical ventilation principles (mixing, displacement or unidirectional airflow distribution) are welldocumented to ventilate the entire room volume. With these principles, usually high amount of air should be supplied to the space to maintain proper IAQ and to reduce the risk of airborne crossinfection. ASHRAE standard for ventilation of health care facilities [6] recommends ventilation rates for general patient rooms to be from 4 to 6 air changes per hour $(\mathrm{ACH})$ and $12 \mathrm{ACH}$ for infectious wards. However, the high ventilation rates will not only increase the associated energy costs. Air velocity in the occupied zone will increase and can cause draught discomfort for occupants. Moreover, experimental studies have documented an interesting phenomenon showing that increased ventilation rate from 6 to $12 \mathrm{ACH}$ in rooms increases the occupants' exposure to cough-released air [7, 8]. Bolashikov et al. [7] suggested that the increased exposure to the coughed air was due to several factors: the air flow interaction in the space, the distance between the exposed person and the source (sick person), posture of the two persons, etc.

People are a source of various airborne odorous contaminants (bio-effluents) that decrease the IAQ. Some hospitalized patients spend most of their time confined to the bed, unable to frequently perform personal hygiene routines. Hence, some of the pollutants found in the air are generated from bacterial decomposition of metabolic byproducts (urine, feces and sweat). For instance, by 
sweating the human body regulates its temperature, but if not removed from the body, sweat can produce a strong odour contributing greatly to the scent known as body odour [9]. As mentioned, the skin microbiota plays an important role for the production of human odours, especially in the conversion of odourless sweat into sweat with its characteristic odour [10]. Some of the main components of the human sweat are ammonia and lactic acid [11, 12]. Ammonia is also one of the compounds that contributes greatly to the offensive odour of human waste (feces and urine) [13]. Ammonia $\left(\mathrm{NH}_{3}\right)$ has an unpleasant odour therefore it can reduce indoor air quality and affect negatively occupants' health and perceived air quality. A questionnaire survey study shows that there is a problem with unpleasant odours in hospitals [14]. The study found that $88.5 \%$ of the nurses sensed odours in hospitals, of whom $81.0 \%$ considered it a problem and $67.2 \%$ recognized a need for improvement. Odours from excrement and urine were answered the most. In bedridden patients, patients with urinary incontinence, patients who use diapers, etc. the odours from excrements were considered the biggest problem.

In the recent years, bed-integrated advanced air distribution methods have been developed and studied for their potential application in hospitals [15-17]. One limitation of these methods is that they mainly focused on controlling and preventing the airborne transmission of infectious diseases due to human expiratory activities, i.e. breathing and coughing. The current study examines the performance of a novel bed-integrated local ventilation unit, known as "ventilated mattress", aiming for reducing the exposure to airborne contaminants (bio-effluents) generated from the lying patients' body $[18,19]$. Part of the surface of the ventilated mattress is designed as an exhaust opening for removing the body emitted pollutants. The idea behind the ventilated mattress (VM) is to capture and to locally exhaust the bio-effluents before they spread into the room (Fig. 1). There is a mesh inside the ventilated mattress which provides body support and allows the exhausted air to move inside the mattress.

Different filtration and air cleaning methods can be used to reduce the exposure to indoor pollutants and thus to improve the IAQ. Typical removal methods for gaseous contaminants work on the principles of physical adsorption and chemical reaction. Activated carbon is one of the most widely used adsorbents. There have been a number of studies on the performance of activated carbon for controlling gaseous pollutants, when it is incorporated in air filters for HVAC systems or used in portable air cleaners [20-23]. However little is known about its application as a localized filter for removing gaseous contaminants within the vicinity of the human body. Recent studies show that textile materials made of acid-treated activated carbon fibres (ACF) can be applied as 
deodorants for the unpleasant odour of ammonia [24, 25]. Bivolarova et al. [24] reported that when the acid-treated ACF material was placed close to the emission source, it reduced the $\mathrm{NH}_{3}$ gas concentration almost to zero. The ACF material is capable of adsorbing alkaline substances, such as ammonia gas, because of its acid treatment [25]. However, the material is not able to adsorb acidic substances.

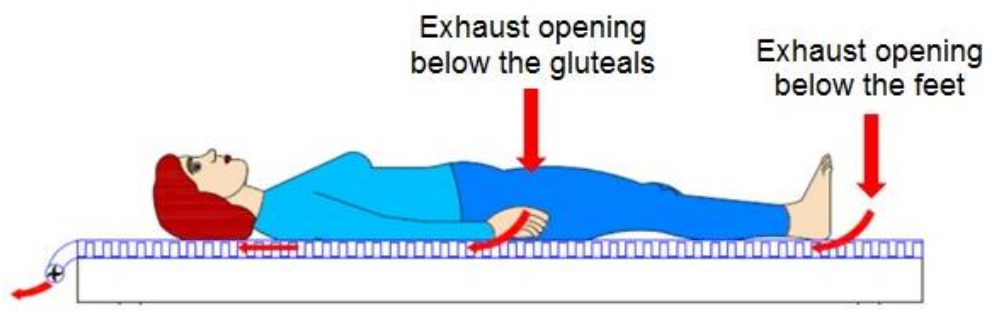

Fig. 1. Ventilated mattress (VM) with two exhaust openings: below the gluteals and below the feet [18].

The application of the VM alone or combined with local air cleaning (in this case acid-treated ACF was used) for improving the IAQ in patient rooms in health care facilities was examined. An objective of this study was to determine if the exposure to airborne contaminants generated from the body will be reduced. An important aim was to investigate if it is efficient to clean the sucked polluted air inside the mattress using the local cleaning and then discharge it back into the surrounding room air. In this way, cleaning of locally polluted air and recirculating it will improve the IAQ and reduce the needed background ventilation rate. The cleaning effect of the ACF used as a patient's body cover (blanket) was studied only to show potential applications of air cleaning materials. It was not an objective of this study to examine the properties of the ACF material.

\section{Methods}

\subsection{Experimental set-up}

The experimental measurements were carried out in a stainless steel climate chamber furnished with a single-bed to simulate a hospital patient room. The dimensions of the chamber were as follows: length $-3.6 \mathrm{~m}$, width $-2.5 \mathrm{~m}$ and height $-2.5 \mathrm{~m}$. The climate chamber was air conditioned using underfloor air distribution supplying $100 \%$ outdoor air at $10 \mathrm{~L} / \mathrm{s}$ (equal to1.6 $\mathrm{ACH}$ ), corresponding to the minimum requirement of supply air flow rate per person or bed for patient rooms, as proposed in the FprCEN/TR 16244 technical report for hospital ventilation [26]. During the measurements, three fans were constantly operating to generate complete mixing in the chamber. The room air was exhausted through a circular opening located on the ceiling (Fig. 2). 

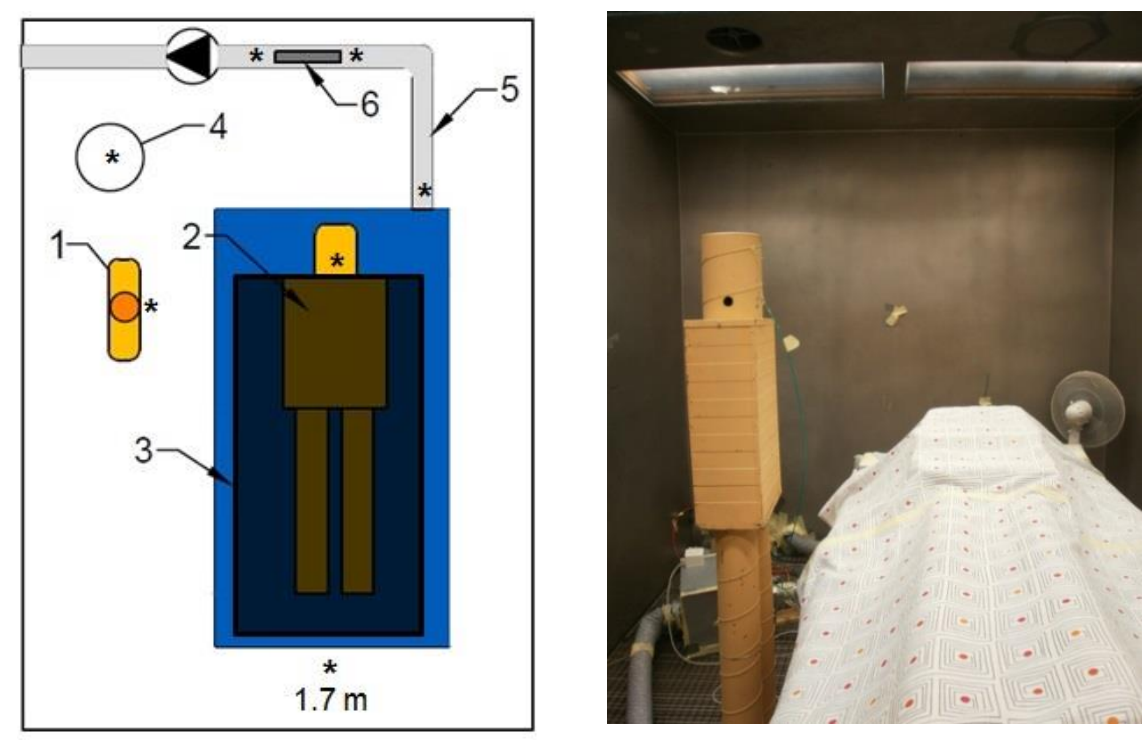

Fig. 2. Experimental setup: (left) Floor plan of the chamber showing the position of the sampling gas tubes (*), where 1 - "doctor", 2 - "patient", 3 - a double bed sheet or ACF material used as a blanket, 4 - total exhaust opening, 5 - exhaust duct of the VM connected to a fan, 6 - 'duct ACF' positon; (right) Interior of the chamber with the standing dummy next to the bed with the ventilated mattress and the lying dummy covered with a sheet.

Two heated dummies were used to simulate a lying patient and a standing doctor next to the patient's bed. The standing dummy was positioned $0.2 \mathrm{~m}$ from the side of the bed near the head of the lying dummy, Fig. 2. Each dummy consisted of 3 parts - "legs", "torso" and "head". The head and legs were made from circular ducts with diameters of $0.2 \mathrm{~m}$ and $0.12 \mathrm{~m}$, respectively. The torso was made from a duct of rectangular cross section with dimensions $0.6 \mathrm{~m}$ x $0.35 \mathrm{~m}$ x $0.2 \mathrm{~m}(\mathrm{H}$ x L x $\mathrm{W})$. The total height of dummies was $1.65 \mathrm{~m}$. Inside each dummy, six light bulbs were operating during the experiments. One bulb was installed in the head, one in the torso and 2 bulbs per each leg. A fan was also positioned in the torso for better mixing of the heated air and thus creating a uniform temperature distribution over the whole surface area of the dummy. The total generated heat power was $62 \mathrm{~W}$ for the "patient" and $130 \mathrm{~W}$ for the "doctor" corresponding to the metabolic heat load of a lying person in rest and standing person in rest, respectively. During the experiments, the legs and the torso of the lying dummy were fully covered with a double bed sheet or in some cases with a piece of the ACF material used as a blanket. In reality, the human body shape is more complex than the simplified figure of the dummy. Therefore, additional small wooden blocks were placed on top of the torso of the lying dummy to create small gaps between the chest and the sheet covering the lying person. 
The studied ventilated mattress (VM) was placed on top of the regular mattress of the bed. The exhaust opening of the VM was located under the area where the legs of the dummy were connected to the torso (i.e. corresponding to the gluteal region of a human body). The dimensions of the local exhaust opening were: $0.8 \mathrm{~m} \times 0.16 \mathrm{~m}(\mathrm{~L} \mathrm{x} \mathrm{W})$. The exhaust opening of the VM was covered with a polyester mesh with free area ratio of about $90 \%$. The surface of the VM was made of synthetic fibre (polyester), which is permeable for air. Thus, the mattress was sealed in nylon from everywhere but the exhaust opening, in order to assure that the exhausted air passed only through the exhaust opening.

The VM was connected to a separate exhaust system. A small axial fan, placed inside the chamber, was connected with a straight duct $(\varnothing 0.08 \mathrm{~m})$ to the VM. Through this separate system the ammonia gas was exhausted from the mattress and discharged out of the chamber. In one experiment (Table 2, case number 5, recirculation case), the exhausted air mixed with ammonia gas was discharged back into the chamber after it was locally cleaned by the ACF material installed within the mattress. The local airflow rate through the VM was measured with the help of an air flow sensor (MFS-C-080) installed in the straight connection between the fan and the VM. The MFS sensor was installed by following the recommendations of the manufacturer to ensure correct readings. The maximum error in the measurement with this sensor is $\pm 3 \%$ of the actual flow. The pressure difference at the MFS sensor was measured with a differential pressure micro-manometer FCO510 (accuracy of $0.01 \mathrm{~Pa}[0.15 \times 10-5 \mathrm{psi}] \pm 0.25 \%$ of reading). The required flow rate was then adjusted by a manually operated damper, based on the pressure difference readings from the micro-manometer. During the experiments when the ventilated mattress was in operation its exhaust air flow rate was kept constant and equal to $1.5 \mathrm{~L} / \mathrm{s}$.

The used activated carbon fibre (ACF) material was nonwoven fabric that had been chemically treated with acid. The nonwoven textile was produced from activated pitch-based carbon fibre. The properties of the studied ACF material are given in Table 1. In this study, the ACF material was: 1) installed as two single rectangular sheets inside the mattress below and above its mesh like a "sandwich" (Fig. 3); 2) a rectangular piece of the ACF fabric was attached to a cylindrical frame which was installed in the exhaust duct of the mattress (Fig. 4) or 3) the ACF fabric was used as a patient's cover/blanket. The size of each sheet of the "sandwich" ACF was $0.8 \times 0.87 \mathrm{~m}^{2}(\mathrm{~L} \times \mathrm{W})$, and the size of the ACF material attached to the cylindrical frame was $0.37 \times 0.13 \mathrm{~m}^{2}(\mathrm{~L} \mathrm{x} \mathrm{W})$. The cylindrical frame had a diameter of $0.037 \mathrm{~m}$ and it was placed in the straight section of the exhaust duct of the ventilated mattress before the fan allowing the airflow along the duct to "wash" the ACF 
material along its two surfaces. The size of the ACF material that was studied as a blanket was 1.54 m (width) x $1.95 \mathrm{~m}$ (length). In order to hold the ACF cover on top of the dummy, a regular double sheet was placed on top of the ACF cover. For every case with the ACF material, a new sample was used at the start of the experiment.

Table 1. Properties of the acid-treated activated carbon fibre material.

\begin{tabular}{ccccc}
\hline $\begin{array}{c}\text { Specific surface } \\
\text { area }\left(\mathrm{m}^{2} / \mathrm{g}\right)\end{array}$ & $\begin{array}{c}\text { Pore volume } \\
(\mathrm{mL} / \mathrm{g})\end{array}$ & $\begin{array}{c}\text { Pore diameter } \\
(\mathrm{nm})\end{array}$ & Thickness $(\mu \mathrm{m})$ & $\begin{array}{c}\text { pH level of the } \\
\text { acid }\end{array}$ \\
\hline 1350 & 0.6 & 1.9 & 17 & 3 \\
\hline
\end{tabular}

To simulate body generated bio-effluents, ammonia gas was released from the lying dummy's "groin" area. A specially designed gas-generator system was used to release the ammonia gas. The gas generator consisted of two gas washing bottles each having an inlet and an outlet nozzle. The inlets were connected to a diaphragm pump, which was supplying fresh air to the washing bottles. The configuration is shown in Fig. 5. The air flow rate of the pump was kept constant $(0.2 \mathrm{~L} / \mathrm{min})$ and controlled by a gas Rotameter. To generate ammonia gas, each washing bottle contained 300 $\mathrm{mL}$ distilled water mixed with $35.3 \mathrm{~mL}$ of $28 \%$ ammonium hydroxide $\left(\mathrm{NH}_{4} \mathrm{OH}\right)$ solution. The two outlets of the washing bottles were connected through tubes to a perforated plastic ball in order to provide a uniform spatial dispersion of the generated ammonia gas. An Innova 1412 Photoacoustic Gas Monitor was used to monitor the $\mathrm{NH}_{3}$ concentration released from the plastic ball in order to ensure that the $\mathrm{NH}_{3}$ concentration was in the desired range. The Gas Monitor was calibrated prior to the experiments and was able to measure ammonia gas up to 6000 parts per million (ppm). The measured $\mathrm{NH}_{3}$ gas concentration at the point of release was approximately $5400 \mathrm{ppm}$ (with a relative error of $2 \%$ ) throughout the whole experiment. In this study, considering the detection limit $(0.1 \mathrm{ppm})$ of the gas Monitor, the tracer gas was dosed at $5400 \mathrm{ppm}$ in order to achieve high enough background concentration of the $\mathrm{NH}_{3}$ gas in the chamber and be able to identify the effect of the $\mathrm{VM}$ and the local cleaning. In practice, the bio-effluent concentrations may be much lower and measured in ppb [27].

The air in the chamber, which was mixed with the ammonia gas, was sampled by two Innova 1303 Multipoint Samplers and its ammonia gas concentration was analysed using a second Photoacoustic Gas Monitor Innova 1312 connected to the two Innova 1303 Samplers. Each of the Innova 1303 samplers had 6 channels. The sampling time of the Innova 1312 was $40 \mathrm{~s} / \mathrm{channel}$ and 12 channels were measured in sequence, giving a period of 8 min between measurements in the 
same location. The Innova gas analyser was calibrated prior to the experiment and its lower detection limit for $\mathrm{NH}_{3}$ gas was $0.1 \mathrm{ppm}$. The measuring error of the instrument was $5 \%$ of the actual value. The $\mathrm{NH}_{3}$ concentration in the chamber was measured at the breathing zone (BZ) of both the "doctor" and the "patient", at the total exhaust opening, and at $1.7 \mathrm{~m}$ height $0.2 \mathrm{~m}$ from the patient's legs. The ammonia gas was sampled in the exhaust duct of the VM, downstream of the "sandwich" ACF, and downstream and upstream of the duct ACF material (Fig. 2). The rest of the channels were placed in several positions outside the chamber as a control measure during the experiment to check if there were leakages from the chamber. No leakages were measured. $\mathrm{No} \mathrm{NH}_{3}$ was measured in the supply air as well.

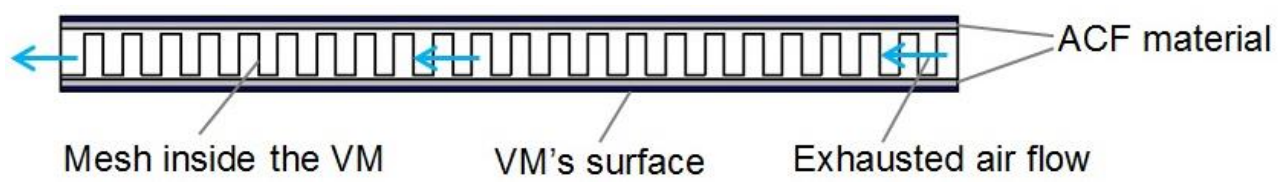

Fig. 3. Diagrammatic representation of the "sandwich" ACF material installed inside the VM.

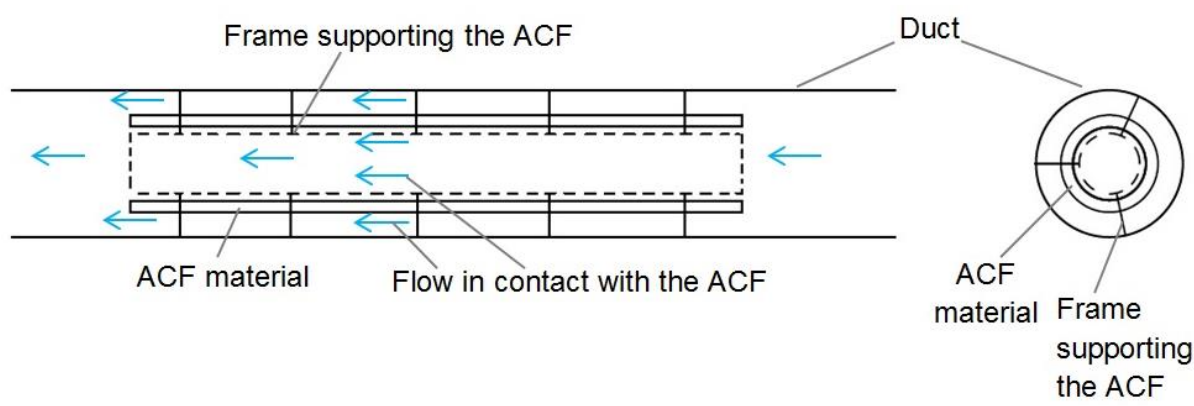

Fig. 4. Diagrammatic representation of the duct ACF material installed inside the exhaust duct connected to the VM.

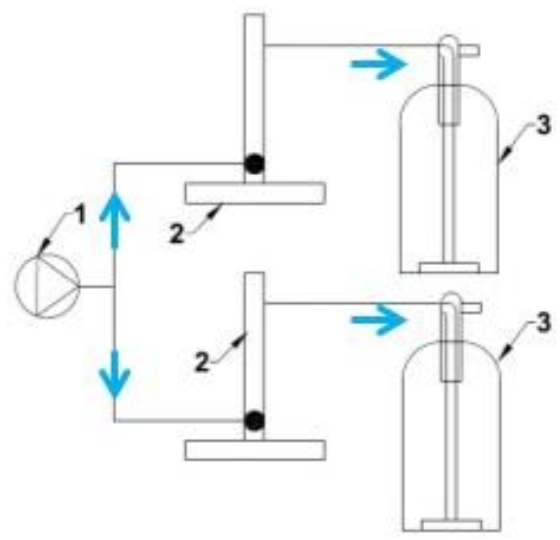

Fig. 5. Diagrammatic representation of the $\mathrm{NH}_{3}$ gas generation setup, where 1 - pump, 2 - gas Rotameter and 3 - washing bottle with $\mathrm{NH}_{4} \mathrm{OH}$ solution. 


\subsection{Experimental conditions}

The chamber was ventilated with 1.6 ACH during all the measurements. The temperature inside the chamber was $29 \pm 1^{\circ} \mathrm{C}$. This temperature was in the range recommended in standards and guidelines for patient rooms $\left(20-32{ }^{\circ} \mathrm{C}\right)$. For instance, conditions of $32{ }^{\circ} \mathrm{C}$ air temperature and $35 \%$ relative humidity has been found beneficial in treating certain types of arthritis [5]. An air temperature of 32 ${ }^{\circ} \mathrm{C}$ is sometimes kept for burn patients and $30^{\circ} \mathrm{C}$ in paediatric surgery [5]. Furthermore, a study on the performance of the method under high room air temperatures is important when considering perceived air quality which, decreases with increase of air temperature and humidity [28]. The ASHRAE standard 170-2013-Ventilation of health care facilities recommends a maximum of $60 \%$ RH in patient rooms [6]. However, in countries with hot and humid climate (e.g. Singapore, Malaysia, Japan, etc.) this recommendation might be difficult to fulfil. Yau and Chu [29] reported that the air temperature in two Malaysian hospitals varied in the range of $20-32.2{ }^{\circ} \mathrm{C}$ and the measured RH varied in the range of $44 \%-79 \%$. Thus, considering the possible practical applications of the studied method, the relative humidity in the chamber was controlled and kept in some experiments at $25 \%$ (with $\pm 5 \%$ relative error) and in some at $70 \%$ (with $\pm 6 \%$ relative error). A HOBO data-logger was used to measure and record the relative humidity in the chamber with an uncertainty of $2.5 \%$. The air temperature in the chamber was measured by an air temperature sensor with an uncertainty of $0.3^{\circ} \mathrm{C}$ as described by Simone et al. [30]. The output from the sensor was logged by a portable data logger.

The experimental conditions comprised (Table 2): 1 - background ventilation alone at $1.6 \mathrm{ACH}$, without the VM was working ('1.6 ACH'); 2 - the ventilated mattress was operating without using the ACF material ("1.6 ACH + VM'); 3 - the VM working and the ACF material installed on the cylindrical frame placed inside the exhaust duct of the VM ('1.6 ACH + VM + duct ACF'); $4-$ the VM working and having the ACF material installed as a "sandwich" ("1.6 ACH + VM + "sandwich" ACF'); 5 - the VM working having the ACF material installed as a "sandwich" with recirculation of the air exhausted by the VM back into the chamber ("1.6 ACH + VM + "sandwich" $\mathrm{ACF}+$ recirculation'); 6 - using only the ACF material as a cover, i.e. the VM was not working, ('1.6 ACH + ACF cover'); 7 - the VM working in conjunction with the ACF used as a cover ('1.6 $\mathrm{ACH}+\mathrm{VM}+\mathrm{ACF}$ cover'). The effect of relative humidity of the room air on the cleaning efficiency of the ACF material was studied at $25 \%$ and $70 \%$ RH (experimental conditions 8 and 9 , Table 2). 
Table 2. Experimental conditions

\begin{tabular}{ll}
\hline № & Conditions at low $\mathbf{R H}=\mathbf{2 5 \%}$ \\
\hline 1 & '1.6 ACH' (reference case) \\
2 & '1.6 ACH+VM' \\
3 & '1.6 ACH + VM +duct ACF' \\
4 & '1.6 ACH + VM + "sandwich" ACF' \\
5 & '1.6 ACH + VM + "sandwich" ACF + recirculation' \\
6 & '1.6 ACH + ACF cover' \\
7 & '1.6 ACH + VM +ACF cover' \\
\cline { 2 - 2 } & Conditions at high RH=70\% \\
\cline { 2 - 2 } 8 & '1.6 ACH' \\
9 & '1.6 ACH + VM + "sandwich" ACF' \\
\hline
\end{tabular}

\subsection{Experimental procedure and exposure assessment}

The total volume ventilation system and the two dummies were switched on all the time to keep the air temperature in the chamber stable. Prior to the experiments with the ventilated mattress in operation, the air flow rate through the mattress was adjusted to $1.5 \mathrm{~L} / \mathrm{s}$. The experiments were started after reaching steady state level of the desired relative humidity. When used, the ACF was set to the desired position prior to the experiment. Afterwards ammonia gas dosing was started. For each condition a newly prepared $\mathrm{NH}_{4} \mathrm{OH}$ solution was used.

One experimental condition lasted approximately 7 hours and 20 minutes (counted from the time when the ammonia gas dosing was started). When steady state, i.e. constant gas concentration at the sampling points was reached, 20 values of the $\mathrm{NH}_{3}$ concentration for each measuring point were acquired. The data were then analysed by averaging all 20 values collected during one experimental condition.

\subsection{Uncertainty of Measurement}

The measured data of ammonia gas concentration were analyzed in accordance with ISO/IEC Guide for the expression of uncertainty [31]. The absolute expanded uncertainty with $95 \%$ confidence interval and coverage factor of 2 was estimated based on the bias and resolution of the Innova instrument as well as the reproducibility (standard deviation) of the measured concentrations. The uncertainties are given in the results as error bars on the column charts or listed in Table 3 for some of the measurement results. 
The repeatability error of the measuring procedure, due to uncertainty in boundary conditions, position of the dummies, etc. was estimated by repeated experiments. Several of the experimental conditions (conditions number 1, $2 \& 6$ in Table 2) were repeated two to five times to quantify if the results were affected by the experimental procedure and the boundary conditions such as the volume air flow rate in the room, the air temperature, the $\mathrm{RH}$ and the dosing rate of $\mathrm{NH}_{3}$ gas. The maximum difference between the repeated measurements was $\pm 0.3 \mathrm{ppm}$.

\section{Results}

Fig. 6 shows the ammonia gas concentration measured in the room as a function of time from the start of dosing the gas. The results in the figure were obtained during the reference case ' $1.6 \mathrm{ACH}$ '. Small fluctuations of the gas concentration are observed in all sampling points except in the breathing zone of the patient after reaching steady state gas concentration (after $277 \mathrm{~min}$ ). The ammonia concentration in the breathing zone of the patient is higher and fluctuates more compared to the rest of the measured points. This may be due to the complex interaction of weak convective flow above the heated "head", a weak flow with high ammonia concentration escaping through the gaps between the sheet and the body at the head region, and the background airflow in the room. This needs to be studied.

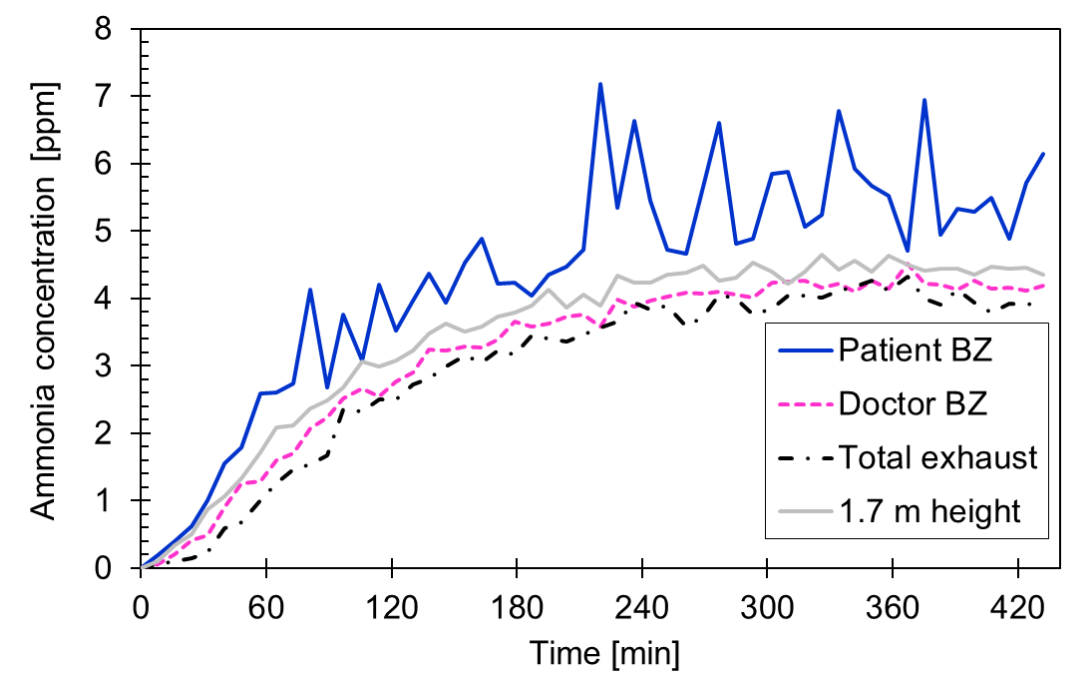

Fig. 6. Ammonia concentration in the sampling points throughout the chamber for the exposure period ( 7 hours $20 \mathrm{~min}$ ) during the condition of ' $1.6 \mathrm{ACH}$ ' (reference case).

\subsection{Exposure reduction}

The exposure reduction in the room due to the effectiveness of the VM and the ACF material was quantified as follows: 


$$
\text { Exposure reduction }=\frac{C_{i, R e f}-C_{i}}{C_{i, R e f}} \times 100 \%
$$

where $\mathrm{C}_{\mathrm{i}}$ is the concentration (ppm) of the contaminant acquired at a measuring point when the VM or $\mathrm{ACF}$ or both were used in the experiment and $\mathrm{C}_{\mathrm{i}, \mathrm{Ref}}$ is the concentration (ppm) acquired at the same measuring point during the reference condition '1.6 ACH' background ventilation only.

Fig. 7 compares the exposure reduction due to the use of the VM alone and when it was combined with the "sandwich" ACF (cases 2 and 5, Table 2). The results indicate that up to $71 \%$ of the body-emitted pollutants were discharged through the ventilated mattress out of the room before they were mixed with the inhaled air (the condition '1.6 ACH + VM' in Fig. 7). The same percentage of exposure reduction (up to73\%) was achieved when the sucked polluted air was locally cleaned inside the VM by the ACF material and recirculated back to the room. In every experiment equal amount of $\mathrm{NH}_{3}$ gas was released from the patient's groins and also the VM exhaust flow rate was kept unchanged, therefore the amount of sucked contaminants in the mattress was the same during the two experiments. Thus, the results in Fig. 7 imply that the sucked polluted air was fully cleaned by the ACF material. Hence, about $30 \%$ of the polluted air was not captured by the local suction and it was therefore mixed with the background room air.

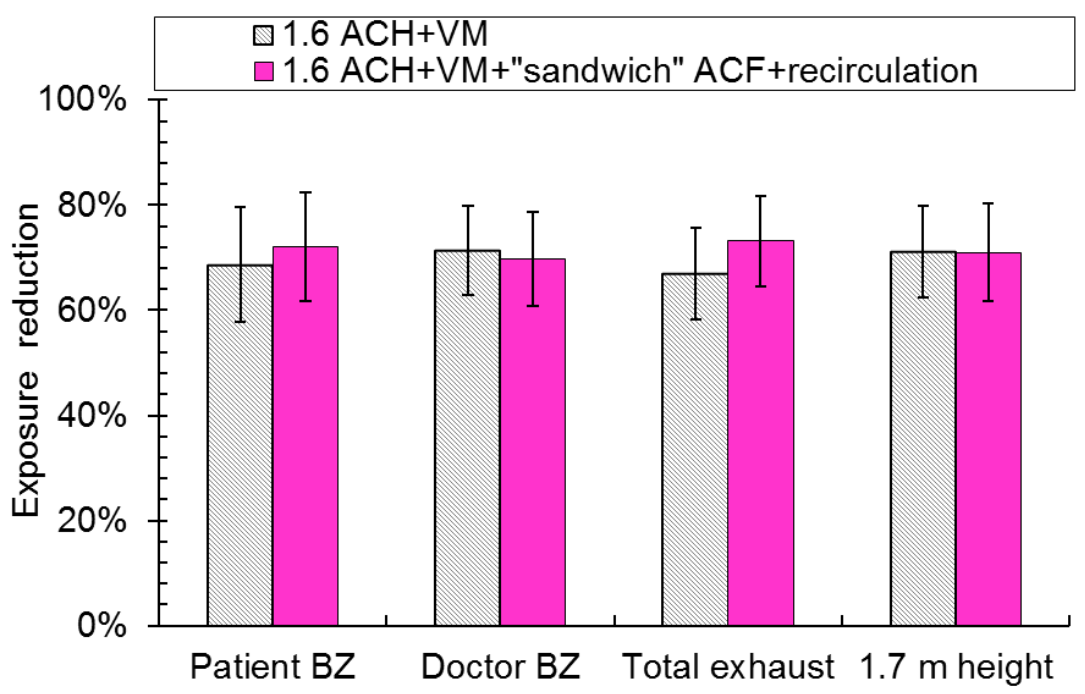

Fig. 7. Exposure reduction using the VM only and VM combined with "sandwich" ACF material relative to the background mixing ventilation alone.

Fig. 8 shows the exposure reduction when the ACF material was used as a cover/blanket for the patient and when the VM and the ACF cover were used together. When only the ACF cover was used, the exposure reduction in all points, except the patient's BZ, was more than $80 \%$. The most significant result in Fig. 8 is that the exposure to ammonia gas was almost entirely reduced (up to 
96\% exposure reduction) when employing both the ventilated mattress and the ACF cover. It should be noted that during this case the ventilated mattress was extracting the pollutants out of the room through the separate exhaust system. Thus, the rest of the pollutants, which were not captured by the VM, were cleaned by the activated carbon fibre cover.

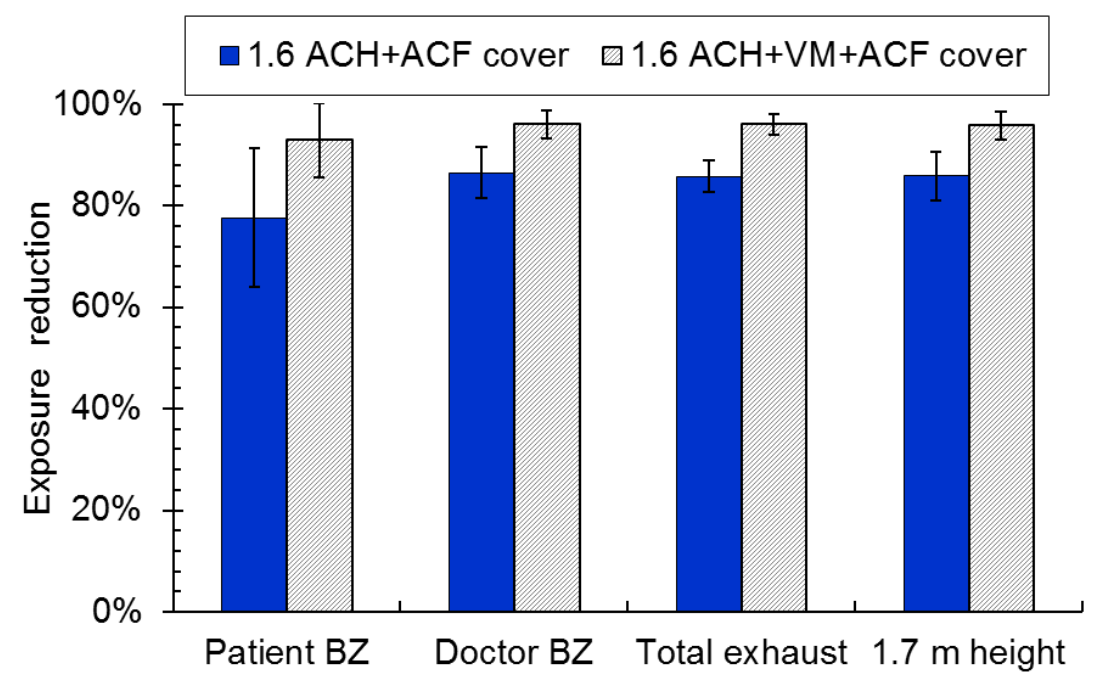

Fig. 8. Exposure reduction using the ACF as a blanket and when using the VM combined with ACF as a cover compared to the case of background mixing ventilation alone.

\subsection{Cleaning efficiency of the ACF material and effect of $R H$}

To investigate the potential use of the acid-treated ACF as a filter for the air exhausted by the VM, two applications were compared. The ACF material was installed either in the VM's exhaust duct (duct ACF) or inside the mattress ("sandwich" ACF), cases 3 and 4 in Table 2. The air cleaning efficiency of the two applications was assessed according to the following equation:

Air cleaning efficiency $=\frac{C_{j}-C_{A C F}}{C_{j}} \times 100 \%$

where in the case of "sandwich" ACF: $\mathrm{C}_{\mathrm{ACF}}$ is the average $\mathrm{NH}_{3}$ gas concentration (ppm) measured in the exhaust duct of the operating ventilated mattress downstream of the ACF material, $\mathrm{C}_{\mathrm{j}}$ is the average ammonia concentration ( $\mathrm{ppm}$ ) measured at the same point when there was no material installed; in the case of the duct ACF: $\mathrm{C}_{\mathrm{j}}$ was measured upstream $3 \mathrm{~cm}$ from the material and $\mathrm{C}_{\mathrm{ACF}}$ was measured downstream $3 \mathrm{~cm}$ from the duct ACF.

The results are listed in Table 3. The air cleaning efficiency of the duct filter was not high (only $23 \%)$. On the contrary, the air cleaning efficiency was high (99\%) when the ACF was placed inside 
the mattress as a "sandwich". The difference in the cleaning efficiency of the two ACF applications is clearly high; hence, it is important the way the material is used. This may be due to the different residence time of the ammonia molecules within the boundaries of the ACF (in the duct and inside the mattress) and also the different total area of the two ACF samples. The objectives of the current study were not to examine the properties of the ACF material. This needs to be studied separately.

For practical applications, it was studied the influence of relative humidity on the air cleaning efficiency of the ACF fabric. The cleaning efficiency of the "sandwich" ACF was studied at 25\% and $70 \%$ room relative humidity. The results listed in Table 3 (cases 2 and 3) show that the increased level of RH did not affect the air cleaning efficiency of the ACF. The air cleaning efficiency at $25 \%$ RH and $70 \%$ RH differed only by $1 \%$.

Table 3. Air cleaning efficiency of the "sandwich" ACF and duct ACF.

\begin{tabular}{ccccc}
\hline № & Application & Relative humidity & $\begin{array}{c}\text { Air cleaning } \\
\text { efficiency }\end{array}$ & $\begin{array}{c}\text { Expanded } \\
\text { uncertainty in } \\
\text { ppm }\end{array}$ \\
\hline 1 & duct ACF & $25 \%$ & $23 \%$ & 2.4 \\
2 & "sandwich" ACF & $25 \%$ & $99 \%$ & 0.02 \\
3 & "sandwich" ACF & $70 \%$ & $98 \%$ & 0.09 \\
\hline
\end{tabular}

The concentration of the sucked by the VM ammonia gas as a function of time is shown in Fig. 9. The measurements were performed in the exhaust duct connected to the VM when there was no ACF material installed. Steady-state in time ammonia concentration with large fluctuations was measured. The $\mathrm{NH}_{3}$ concentration measured downstream of the "sandwich" ACF filter when the material was exposed to $25 \%$ and $70 \%$ relative humidity is shown in Fig. 10. It is apparent from these two figures (Fig. 9 and Fig. 10) that the ACF material has high cleaning effectiveness. In Fig. 10 , however, there is a trend for the ammonia concentration to increase at the end of the exposure. When the relative humidity in the chamber was $70 \%$, the cleaning efficiency of the ACF material was started to decrease after approximately 6 hours of ammonia exposure. These results suggest that after exposure for longer than 7 hours, the efficiency of the tested ACF may decrease significantly at $70 \% \mathrm{RH}$. 


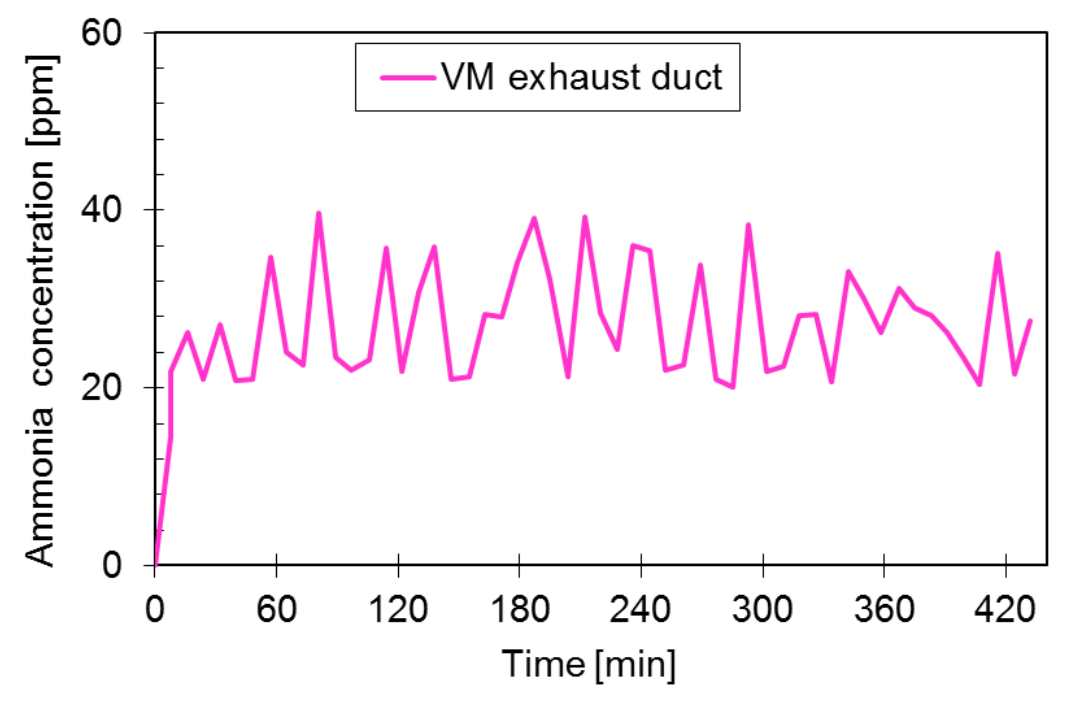

Fig. 9. Ammonia gas concentration measured in the exhaust duct of the VM when there was no ACF material installed.

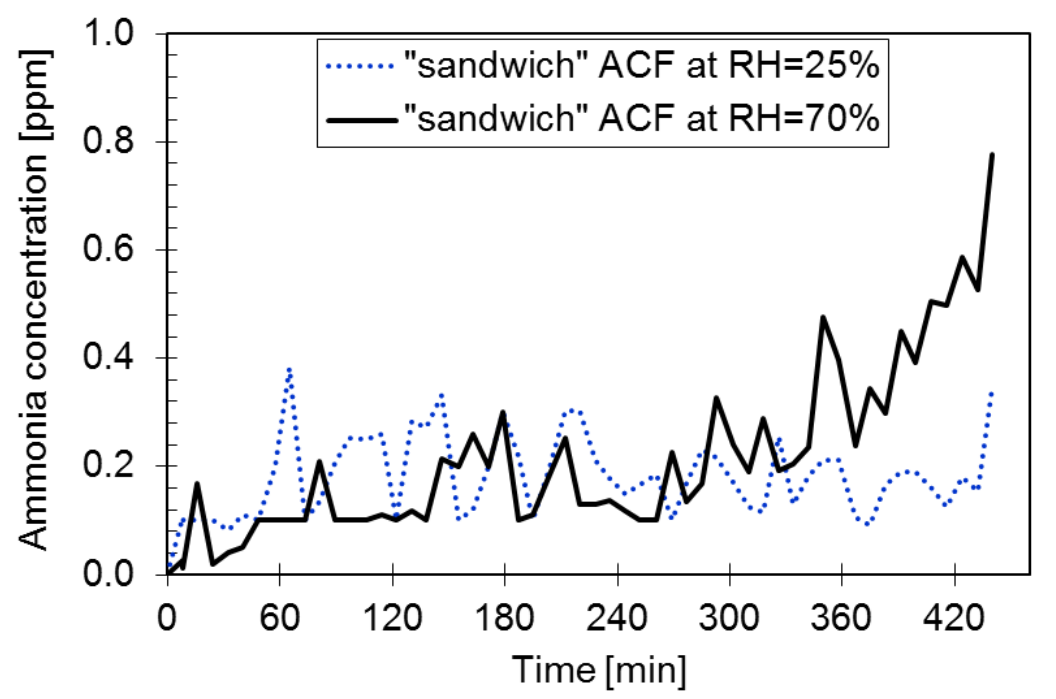

Fig. 10. Ammonia gas concentration measured in the exhaust duct of the VM downstream of the "sandwich" ACF material in the cases the relative humidity was $25 \%$ and $70 \%$ in the room.

\section{Discussion}

Melikov [32] has reported that airflow interaction in the micro-environment of a person has a major effect on exposure to pollution generated at the vicinity of the body. Thus, in order to improve inhaled air quality, it is needed the air flow interaction around the human body to be locally controlled. The results of the present study show that the VM and the ACF material, used as a pollution control strategy, substantially reduce the exposure to ammonia gas under low room background ventilation rate of $1.6 \mathrm{ACH}(10 \mathrm{~L} / \mathrm{s})$. 
An important finding is that the ventilated mattress can be used to improve the IAQ even when it is not connected to a separate exhaust system. The method of incorporating the ACF material inside the mattress to clean the sucked polluted air and then recirculated it back to the room proved to be an effective measure for exposure reduction to groin-generated $\mathrm{NH}_{3}$ gas (Fig. 7). Other body parts which are sources of human bio-effluents are the underarms and feet [33]. The ability of the ventilated mattress to remove different tracer gases dosed from the armpits and feet of a lying thermal manikin has been previously studied and shown to be highly efficient ventilation method $[18,19]$. It can therefore be expected that in the future the VM equipped with new materials that clean wide spectrum of bio-effluents will be more efficient. Moreover, the recirculation mode of operation of the VM will avoid using additional ducting and making changes in already existing background room system for ventilation. This will increase the flexibility of the patient's bed location as well, allowing the bed to be moved around.

Interestingly, when using only the ACF as a patient's cover it was observed that the exposure to ammonia decreased more compared to using only the ventilated mattress. Such method of local air cleaning will be much more efficient in practice than the widely used room air cleaners. However, there are limits of applying cleaning textiles as a cover. In reality, the patient will move and thus the body odours may escape before reacting with the material. Hospital clothing for the patients and bed linens made from different air cleaning textiles could be a solution.

In all measurements the exhaust air flow rate of the VM was adjusted to $1.5 \mathrm{~L} / \mathrm{s}$ which managed to capture about $70 \%$ of the ammonia gas. The efficiency of the VM was studied in separate experiments at different exhaust airflow rates, blanket/cover arrangements and background air distribution. The results will be presented in a separate paper.

The combined together localized ventilation and air cleaning methods, namely the VM and ACF cover, can achieve more than $90 \%$ high exposure reduction, as the results in Fig. 8 show. This result support the idea that when applying local control strategies close to the source it can be much more effective approach to reduce the exposure of occupants to airborne contaminants generated indoors than using background air distribution to dilute within the entire space. The high exposure reduction efficiency of the ACF fabric applied as a cover/blanket for the patient is a good illustration of the potential use of existing, new and forthcoming textile materials in conjunction with the VM. Recently, a new non-woven fabric coated with nanoparticles that has antibacterial effect has been introduced on the market [34]. The new material can inactivate different bacteria including methicillin-resistant Staphylococcus aureus (MRSA), Klebsiella pneumonia, Bacillus coli, etc. 
MRSA is a bacterium known to be resistant to many antibiotics and is still a major patient threat in hospital environments [35]. It has been shown that desquamated skin flakes from the body can be carriers of the pathogenic bacteria [36]. Another study reported that some of the frequently contaminated objects in a hospital included also the bed linens and the patient's gown [37]. It has been shown that it is likely particles deposited on mattresses and blankets to resuspend and reach the breathing zone of the lying person [38]. One viable solution for purifying the inhaled air in hospital patient rooms can be the use of textile materials with antibacterial and deodorizing properties in form of covers, bed linens, gowns, etc.

Bivolarova et al. [24] reported that the acid-treated ACF material's removal efficiency was not affected by changes of the air temperature, from $20^{\circ} \mathrm{C}$ to $28^{\circ} \mathrm{C}$, and only slightly was reduced in the case of an increase of the relative humidity from $25 \%$ to $80 \%$. The current study found that the ventilated mattress can efficiently work when it was equipped with the "sandwich" ACF at room air temperature of $29^{\circ} \mathrm{C}$. It was found that when the ACF material was used to cover the inside mesh of the mattress the measured ammonia concentration downstream of the material was almost entirely reduced under room conditions of $29^{\circ} \mathrm{C}$ and $25 \% \mathrm{RH}$. The same result was obtained when the room relative humidity was increased from $25 \%$ to $70 \%$ (Table 3 ). These results show that the VM combined with the ACF material can be used also in countries with hot and humid climate.

Only a slight decrease in the cleaning efficiency of the "sandwich" ACF was observed at the end of the exposure when the relative humidity in the chamber was 70\% (Fig.10). A study by Lee and Davidson [20] showed that the adsorption efficiency of different type of activated carbon fibre decreased when the relative humidity was increased from $20 \%$ to $50 \%$. The mechanism for this effect of humidity was believed to be that micro-pores in the activated carbon were blocked by water molecules, leaving a reduced number of sites for the adsorption of gas molecules. In the present study, an effect of increase in RH level on the performance of the acid-treated ACF material was not observed. This could be explain with the fact that ammonia reacts with a number of acids, thus the air cleaning effect of the ACF occurs due to chemical adsorption (chemisorption). Normally, water vapour facilitates chemisorption, whereas it usually hinders physical adsorption [39]. This, however, means that lower than $25 \% \mathrm{RH}$ level might decrease the ACF performance. In general, there are existing analytical and empirical models for estimating the gas-phase filter breakthrough time and adsorption capacity at different gas concentrations and RH levels [40, 41].

The findings in the present study may be somewhat limited by factors such as body posture of the person lying on the mattress, different bedding arrangements and effect of human respiratory 
rate on the inhaled pollutants. In the study by Bivolarova et al. [19], it was found that when a person is lying on his/her stomach this may decrease to some extent the ability of the ventilated mattress to capture pollutants emitted from his/her armpits. Further studies, which take these variables into account, will need to be undertaken.

Another issue related to the ventilated mattress is whether the air movement through the mattress will provide local body cooling which may cause thermal discomfort. In fact, this has been already tested in a recent study involving a thermal manikin lying on the VM [42]. The results of the study indicated that the ventilated mattress provided cooling to the body parts in contact with the surface of the mattress at 23,26 and $29{ }^{\circ} \mathrm{C}$ room air temperature. The cooling was increased with the increase of the airflow rate through the mattress from $1.5 \mathrm{~L} / \mathrm{s}$ to 3,6 and $10 \mathrm{~L} / \mathrm{s}$. It was suggested in the study that the use of the VM at elevated room temperature will decrease the local warm thermal sensation especially at the back side and the back. This effect of the mattress will be beneficial for bedridden people who are exposed to elevated air temperatures. However, the large differences in local thermal sensation as a result of the non-uniform body cooling may cause thermal discomfort. At the comfortable range of room air temperature (i.e. $21-25^{\circ} \mathrm{C}$ ), the surfaces of the VM in contact with the body can be heated under individual control of user to provide comfort. Noise can be also an issue to be considered when the VM is used in practice. The performance of the VM should be studied with human subjects.

The present hospital HVAC systems are usually designed to ventilate the entire room volume in order to dilute the concentration of the airborne pollutants and to provide comfortable environment. This method in order to be effective needs careful considerations of the type and location of the room supply and exhaust diffusers in relation to the room geometry, temperature difference between supply air and room air, etc. [5]. Energy and money can be saved by conditioning and ventilating only the occupied zone of spaces or part of it, which will require less air. The studied method goes beyond this and provides the possibility for effective control strategy for reduction of indoor exposure to body-emitted contaminants at decreased ventilation rate. Energy will be saved.

The application of the VM has a potential to increase flexibility in the use of hospital rooms. The HVAC system in all patients' rooms can be designed to maintain $3 \mathrm{ACH}$. In the rooms where higher ACH rate is required, the additional improvement of the IAQ can be achieved with the use of the local exhaust ventilation (VM) and an air cleaning material. The VM can be also combined with the personalized hospital bed ventilation suggested by Melikov et al. [16] for preventing airborne spread of infectious respiratory diseases. An optimal control of the air pollutants generated from 
both the body and the respiratory activities of patients can be provided using these two local ventilation methods.

\section{Conclusions}

In this study, measurements in a full-scale mock-up of a hospital patient room were carried out to assess the performance of bed-integrated local exhaust. Ammonia gas was used to simulate a constant emission of airborne pollution from the groins of a lying in bed patient. Acid-treated ACF material, which is able to clean air from ammonia, was used for local cleaning method.

The results show that the ACF fabric applied as a patient's cover/blanket is an effective way of reducing exposure to ammonia gas by more than $80 \%$. The combined use of the VM and ACF cover was the most efficient exposure reduction strategy, since more than $90 \%$ of the ammonia gas in the room air was removed.

$70 \%$ exposure reduction was achieved, when the air exhausted through the VM was removed from the room. Exposure reduction of about $70 \%$ was achieved also when the captured polluted with ammonia air was cleaned with the ACF material inside the VM and afterwards was discharged it back to the room.

An increase in relative humidity from $25 \%$ to $70 \%$ did not decrease the ACF's removal efficiency. This result is promising for applications in spaces in which humidity may vary over a wide range. The studied principle of local air exhaust combined with local cleaning can have broader application not only in health care facilities but also in elderly homes, hotels, and transportation.

Further research might explore the effect of body posture, bedding arrangement and human respiratory rate on the exposure reduction efficiency of the VM. It is important also to study human response to the VM.

\section{Acknowledgement}

This work was partially supported by the European Union 7th framework program HEXACOMM FP7/2007-2013 under grant agreement No 315760 and partially by Grant-in-Aids No.22300249 of the Ministry of Education of Japan. 


\section{References}

[1] ISIAQ. ISIAQ review on indoor air quality in hospitals and other health care facilities. International Society of Indoor Air Quality and Climate, 2003.

[2] Hellgren U-M, Reijula K. Indoor-air-related complaints and symptoms among hospital workers. Scand J Work Environ Health 2006; 32(Suppl 2):47-9.

[3] Nordstrom K, Norback D, Akselsson R. Influence of indoor air quality and personal factors on the sick building syndrome (SBS) in Swedish geriatric hospitals. Occup Environ Med 1995; 52(3):170-6.

[4] Li Y. IAQ Applications: Natural Ventilation Use. ASHRAE Journal 2013; v. 55 n. 5, p. 78-82

[5] ASHRAE. HVAC Design Manual for Hospitals and Clinics. 1st Edition 2003,Atlanta, GA: American Society of Heating, Refrigerating, and Air-conditioning Engineers.

[6] ASHRAE. ANSI/ASHRAE Standard 170-2013, Ventilation of Health Care Facilities. Atlanta: American Society of Heating, Refrigerating and Air-Conditioning Engineers, Inc., 2013.

[7] Bolashikov ZD, Melikov AK, Kierat W, Popiołek Z, Brand M. Exposure of health care workers and occupants to coughed airborne pathogens in a double bed hospital patient room with overhead mixing ventilation. HVAC\&R Research 2012; issue 18(04), pp.602-615.

[8] Pantelic J, Tham KW. 2013. Adequacy of air change rate as the sole indicator of an air distribution system's effectiveness to mitigate airborne infectious disease transmission caused by a cough release in the room with overhead mixing ventilation: A case study. Science and Technology for the Built Environment 19:947-61.

[9] Yamazaki S, Hoshino K, Kusuhara M. Odor associated with aging. Anti - Aging Medicine 2010;7: 60-65.

[10] Verhulst NO, Takken W, Dicke M, Schraa G, Smallegange RC. Chemical ecology of interactions between human skin microbiota and mosquitoes. FEMS Microbiol. Ecol. 2010; 74, 1-9.

[11] Noble WC, Somerville DA. Microbiology of Human Skin.W.B. Saunders Company Ltd 1974, London.

[12] Robinson S, Robinson AH. Chemical composition of sweat. Physiol Rev 1954; 34 : 202-220

[13] Nishida K, Kodama T, Yamakawa M. The changes in psychophysical coefficient by the composition of nightsoil. Kankyo Gijytsu 1981; 10, 462- 473.

[14] Itakura T, Mitsuda M. Servey of characteristics of the odor in medical facilities. The 6th International Conference on Indoor Air Quality, Ventilation \& Energy Conservation in Buildings IAQVEC 2007, Oct. 28 - 31, Sendai, Japan.

[15] Melikov AK. Advanced Air Distribution. ASHRAE Journal 2011; vol. 53, no. 11, pp. 73-77.

[16] Melikov AK, Bolashikov ZD, Georgiev E. Novel ventilation strategy for reducing the risk of cross infection in hospital rooms. Proceedings of Indoor Air 2011;Paper 1037.

[17] Nielsen P, Jiang H, Polak M. Bed with integrated personalized ventilation for minimizing of cross infection. In Proceedings of Roomvent 2007; the 10th International Conference on Air Distribution in Rooms. 
[18] Bivolarova MP, Melikov AK, Kokora M, Mizutani C, Bolashikov ZD. Novel bed integrated ventilation method for hospital patient rooms. Proceedings of Roomvent 2014; 13th SCANVAC International Conference on Air Distribution in Rooms. pp. 49-56.

[19] Bivolarova MP, Melikov AK, Kokora M, Bolashikov ZD. Performance Assessment of a Ventilated Mattress for Pollution Control of The Bed Microenvironment in Health Care Facilities, Healthy Buildings 2015, ISIAQ International Conference, Eindhoven, the Netherlands, May 18-20, paper ID 633.

[20] Lee P, Davidson J. Evaluation of activated carbon filters for removal of ozone at the PPB level. American Industrial Hygiene Association Journal 1999; 60, (5), 589-600.

[21] Sidheswaran M, Destaillats H, Sullivan D, Cohn S, Larsen J, Fisk W. Energy efficient indoor VOC air cleaning with activated carbon fiber (ACF) filters. Building and Environment 2012; 47, 357-367.

[22] Cal MP, Rood MJ, Larson SM. Gas phase adsorption of volatile organic compounds and water vapor on activated carbon cloth. Energ. Fuel 1997;11(2):311-5.

[23] Khazraei Vizhemehr A, Haghighat F, Lee CS, Kholafaei H. Evaluation of Gas-Phase Filter Performance for a Mixture Gas. CSAWAC 43 (4) 463-620 (2015) · Vol. 43 • No. 4

[24] Bivolarova MP, Mizutani C, Melikov AK, Bolashikov ZD, Sakoi T, Kajiwara K. Efficiency of deodorant materials for ammonia reduction in indoor air. In Proceedings of Indoor Air 2014. International Society of Indoor Air Quality and Climate. pp. 573-580.

[25] Mizutani C, Bivolarova MP, Melikov AK, Bolashikov ZD, Sakoi T, Kajiwara K. Air cleaning efficiency of deodorant materials under dynamic conditions: effect of air flow rate. In Proceedings of Indoor Air 2014. International Society of Indoor Air Quality and Climate; pp. 745-749.

[26] FprCEN/TR 16244. Ventilation for hospitals. Technical report 2011, FprCEN/TR 16244:2011: E.

[27] Wang TC. A study of bio-effluents in a college classroom. ASHRAE transactions, 1975; Volume 82, Part I.

[28] Fang L, Wyon DP, Clausen G, Fanger PO. Impact of indoor air temperature and humidity in an office on perceived air quality, SBS symptoms and performance. Indoor Air 2004; Volume 14 Suppl. 7, pp. 74-81.

[29] Yau YH, Chew BT. Thermal comfort study of hospital workers in Malaysia. Indoor Air 2009; 19: 500 - 510. doi:10.1111/j.1600-0668.2009.00617.x

[30] Simone A, Olesen B, Stoops J, Watkins AW. Thermal comfort in commercial kitchens (RP1469): Procedure and physical measurements (Part 1). HVAC\&R Research 2013, Issue 19, pp. 1001-1015.

[31] ISO/IEC Guide. Evaluation of measurement data - Guide to the expression of uncertainty in measurement. ISO/IEC Guide 98-3:2008.

[32] Melikov AK. Human body micro-environment: The benefits of controlling airflow interaction. Building and Environment 2015: 91, 70-77. doi:10.1016/j.buildenv.2015.04.010

[33] Dormont, L., Bessiere, J., Cohuet, A. Human Skin Volatiles. J Chem Ecol, vol.39. 2013, pp.569-578. Available from: doi: 10.1007/s10886-013-0286-z. 
[34] NBC Meshtec Inc., http://www.nbc-jp.com/eng/product/cufitec/ Last accessed on 23. January, 2016.

[35] Centers for Disease Control and Prevention (CDC) http://www.cdc.gov/mrsa/index.html Last accessed on 23. January, 2016.

[36] Davies RR, Noble WC. Dispersal of bacteria on desquamated skin. Lancet 1962; 2: $1295 \pm 7$.

[37] Boyce JM, Potter-Bynoe G, Chenevert C, King T. Environmental Contamination Due to Methicillin-Resistant Staphylococcus aureus: Possible Infection Control Implications. Infection Control and Hospital Epidemiology Vol. 18, No. 9 (Sep., 1997), pp. 622-627.

[38] Spilak MP, Boor BE, Novoselac A, Corsi RL. Impact of bedding arrangements, pillows, and blankets on particle resuspension in the sleep microenvironment. Building and Environment 81 (2014) 60-68. doi:10.1016/j.buildenv.2014.06.010

[39] ASHRAE. 2011. ASHRAE Handbook-HVAC Applications, Chapter 46, Control of Gaseous Indoor Air Contaminants. Atlanta: ASHRAE.

[40] Khazraei Vizhemehr A, Haghighat F, Lee CS. Predicting gas-phase air-cleaning system efficiency at low concentration using high concentration results: development of a framework. Build Environ 2013; 68:12 - 21.

[41] Khazraei Vizhemehr A, Haghighat F. Gas-phase filters breakthrough models at low concentration - Effect of relative humidity. Build Environ 2014; 75:1 - 10.

[42] Bivolarova MP, Melikov AK, Kokora M, Bolashikov ZD. Local Cooling of The Human Body Using Ventilated Mattress in Hospitals, Proceedings of ROOMVENT 2014, 13th SCANVAC International Conference on Air Distribution in Rooms, October 19-22, 2014, Sao Paolo, Brazil, p. 279-286. 